\title{
The role of hepatocyte growth factor activator inhibitor-1 (HAI-1) as a prognostic indicator in cervical cancer
}

\author{
KEIICHIRO NAKAMURA ${ }^{1}$, FERNANDO ABARZUA ${ }^{2}$, ATSUSHI HONGO ${ }^{1}$, JUNICHI KODAMA ${ }^{1}$, \\ YASUTOMO NASU $^{2}$, HIROMI KUMON ${ }^{2}$ and YUJI HIRAMATSU ${ }^{1}$
}

Departments of ${ }^{1}$ Obstetrics and Gynecology, and ${ }^{2}$ Urology, Okayama University Graduate School of Medical, Dentistry and Pharmaceutical Sciences, Okayama, Japan

Received March 13, 2009; Accepted May 14, 2009

DOI: 10.3892/ijo_00000333

\begin{abstract}
Hepatocyte growth factor activator inhibitor-1 (HAI-1) is a Kunitz-type serine protease inhibitor that has a broad inhibitory spectrum against serine proteases. This is the first study to investigate the role of HAI-1 and its clinical importance in cervical cancer. We attempted to investigate the inhibitory effects of HAI-1 using cervical carcinoma cell lines SiHa with integrated human papillomavirus (HPV) 16 and HeLa with integrated HPV 18. HAI-1 expression in cervical cancer $(n=91)$ were assessed by immunohistochemistry. HAI-1 was found to be a potential inhibitory effects mediated by reduction of hepsin, matriptase and prostasin expression. This led to apoptosis through a reduction in the levels of Bcl-2, Bcl-xL, MUPP-1 and MAGI-3 in cervical cancer cell lines. There were significant correlations between HAI-1 expression and stage $(\mathrm{p}=0.013)$, tumor size $(\mathrm{p}=0.002)$, stromal invasion $(\mathrm{p}<0.001)$, vaginal invasion $(p=0.031)$, parametrial invasion $(p=0.012)$, lymph-node metastasis $(p=0.019)$, and LVS involvement $(p=0.002)$. The disease-free and overall survival rates of patients exhibiting high HAI-1 expression were significantly higher than those of patients exhibiting low HAI- 1 expression ( $\mathrm{p}=0.022$ and $\mathrm{p}=0.011$, respectively). The present study proposes that these findings may be considered HAI-1 as a therapeutic target for
\end{abstract}

Correspondence to: Dr Keiichiro Nakamura, Department of Obstetrics and Gynecology, Okayama University Graduate School of Medicine, Dentistry and Pharmaceutical Sciences, 2-5-1 Shikatacho, Okayama 700-8558, Japan

E-mail: k-nakamu@cc.okayama-u.ac.jp

Abbreviations: HAI-1, hepatocyte growth factor activator inhibitor-1; HPV, human papillomavirus; uPA, urokinase plasminogen activator; HGF, hepatocyte growth factor; HGFA, HGF activator; KDs, Kunitz-type serine proteinase domains; LDL, low-density lipoprotein; DMEM, Dulbecco's modified Eagle's medium; FBS, fetal bovine serum; FIGO, International Federation of Gynecology and Obstetrics; PI, propidium iodide

Key words: hepatocyte growth factor activator inhibitor-1, cervical cancer, apoptotic pathway, therapeutic target, favorable prognostic marker treatment and identify as a favorable prognostic marker for cancer patients of cervical cancer.

\section{Introduction}

Cervical cancer is the most important manifestation of human papillomavirus (HPV) infection and is one of the leading causes of cancer mortality in women worldwide. The causal roles of some high-risk HPV types in cervical carcinogenesis has now been clearly established by studies that take into account the many molecular, epidemiological, virological, cytological and histological complexities of the natural history of the disease (1).

Cell surface proteolysis is suggested to play a major role in cancer progression and metastasis through the processing of macromolecules important for regulating the extracellular environment. The cell surface localization, high activity, and exquisite specificity of the type II transmembrane serine protease suggest a role in outside-in signaling and interaction with the microenvironment. Members of the type II transmembrane serine protease family, such as hepsin and matriptase are highly expressed in many cancers, including those of the cervix, prostate, breast and ovarian cancer (2-6). Matriptase and hepsin have been proposed to initiate signaling and proteolytic cascades through its ability to activate prourokinase plasminogen activator (uPA) (7-9). Matriptase is known to interact with the glycosylphosphatidylinositolanchored membrane serine protease of prostasin (10). Matriptase, hepsin and prostasin are potential candidates for the cellular activities of pro-hepatocyte growth factor (proHGF) in cancer tissues (11-13). Importantly, the activities of these proteinases are closely controlled in the pericellular microenvironment by HGF activator (HGFA) inhibitor (HAI). HAI is a type I transmembrane protein with two Kunitz-type serine proteinase domains (KDs) and in its extracellular portion. Two types of HAI have been identified so far, HAI-1 and HAI-2, both of which show cell surface expression on epithelial cells. Therefore, overall structures of the characteristic domains are very similar between HAI-1 and HAI-2. In addition, between KDs, HAI-1 has the ligand binding region of low-density lipoprotein (LDL) receptor. HAI-1 is synthesized as a transmembrane protein on the cell surface and appears to be subsequently shed, but membraneform HAI-2 cannot. The membrane-bound HAI-1 is able to 
form a complex with active HGFA and may function to temporarily sequester HGFA to the cell surface and serve as a reservoir for HGFA (14). The shed form of HAI-1 is active in inhibiting HGFA, matriptase, hepsin and prostasin, all of which are pro-HGF activators $(11,15,16)$. The functional relevance of HAI-1 inhibition of matriptase was confirmed in a transgenic mouse model in which matriptase-induced skin tumorigenesis was completely prevented by the overexpression of HAI-1 in the same tissue (17). To date, several studies on HAI-1 expression in tumor tissues have been published. In prostate, breast and gastric cancer it has been reported that the reduced expression of HAI-1 is possibly involved in the cancer progression (18-20). However, it is not clear how HAI-1 is involved that the role of HAI-1 in cervical cancer.

In order to shed light on the role of HAI-1 in cervical cancer, we examined whether HAI-1 protein expression correlates with clinicopathological characteristics in patients suffering from cervical cancer. The main aim of this study was to determine whether HAI- 1 protein could be considered as a therapeutic target for treatment and used as a favorable prognosis marker for patients of cervical cancer.

\section{Materials and methods}

Cell culture, media and generation of transfectants. HeLa (ATCC no. CCL-2), Caski [Japanese Collection of Research Bioresources (JCRB) no. IFO50007], SiHa (ATCC no. HTB35) and Yumoto cancer cell lines were derived from human cervical carcinomas. Yumoto cells were kindly provided by Dr A. Mitsuhashi (Chiba University, Chiba, Japan), as described previously (21). HPV 16 type Caski and SiHa cell lines, 18 type HeLa cell lines and non-HPV type Yumoto were maintained in Dulbecco's modified Eagle's medium (DMEM, Invitrogen, Carlsbad, CA), supplemented with $10 \%$ fetal bovine serum (FBS) at $37^{\circ} \mathrm{C}$ in an atmosphere with $5 \%$ $\mathrm{CO}_{2}$ in air. A cDNA encoding the whole coding region of HAI-1 was constructed by polymerase chain reaction using full-length HAI-1 cDNA as a template. Primers used were, 5'-TTGGAATTCGCGATGGCCCCTGCGAGGAC-3' and 5'-TTAGTCGACTCAGAGGGGCCGGGTGGTGT-3' for HAI-1. The polymerase chain reaction products were subcloned into the EcoRI/SalI site of an expression plasmid pCIneo (Promega, Madison, WI). A HAI-1 cDNA expression vector was transfected into all cervical cancer cell lines using TransFast transfection reagent (Promega). Mock transfected cells served as a control.

Western blotting analysis. Cell lysates were collected and estimated using a Protein Assay system (Bio-Rad, Hercules, CA) according to the manufacturer's protocols. Proteins from each cell line were subjected to SDS-PAGE and were transferred onto a nitrocellulose membrane. The polyclonal and monoclonal antibodies used for immunoblotting were as follows: HAI-1, matriptase, prostasin, Bcl-2, Bcl-xL, MUGG-1 and MAGI-3 (Santa Cruz Biotechnology, Santa Cruz, CA), hepsin (Cayman Chemical, Ann Arbor, MI) and $\beta$-actin (Sigma Chemical, St. Louis, MO). The working dilution of all primary antibodies was 1:1000. After incubation of membranes with the appropriate secondary antibodies, antigen-antibody complexes were detected using an enhanced chemiluminesence kit (Amersham Biosciences, Piscataway, NJ).

Matrigel invasion assay. To investigate differences in the invasive abilities of cells expressing HAI-1, we used BioCoat Matrigel Invasion Chambers (BD Bioscience, Bedford, MA). $\mathrm{SiHa}$ and HeLa cervical cancer cells with or without transient transfection of the HAI-1 vector were incubated in situ with $10 \mu \mathrm{g} / \mathrm{ml}$ of DiI (Invitrogen) in DMEM containing 10\% FBS for $1 \mathrm{~h}$. The labeled cells $\left(5 \times 10^{4}\right)$ of each genotype were then added to the chambers inserts, and $0.75 \mathrm{ml}$ of medium was added to the bottom of each well. After $48 \mathrm{~h}$ of incubation, the membranes were removed from the insert and mounted on slides, and the numbers of invading cells were counted under the microscope. The matrigel assays were performed in triplicate.

MTS assay. The effects of HAI-1 on cell proliferation were evaluated using the MTS assay (Promega). Cells were seeded into 96-well plates and cultured until the cell density reached $5 \times 10^{4}$ cells/well. The cells were then transiently transfected with the HAI-1 vector for $48 \mathrm{~h}$. After incubation with MTS for $1 \mathrm{~h}$, the absorbances were measured at a wavelength of $490 \mathrm{~nm}$ using an ELISA plate reader (Bio-Rad Systems).

Cell cycle and FITC-conjugated Annexin $V$ analysis. The cells subjected to transient transfection of the HAI-1 vector were trypsinized, washed twice with phosphate-buffered saline, incubated with trypsin for $10 \mathrm{~min}$ at room temperature, incubated with trypsin inhibitor and RNase buffer for $10 \mathrm{~min}$ at room temperature, and stained with $200 \mu 1$ propidium iodide staining solution for $10 \mathrm{~min}$ in the dark, at room temperature (Becton-Dickinson, San Jose, CA). Finally, the cell cycles were analyzed with the FACS cytometer. In addition, apoptosis was measured by staining with FITCconjugated Annexin V using a MEBCYTO apoptosis kit (MBL, Nagoya, Japan) according to the manufacturer's recommendations and flow cytometry analysis $\left(\right.$ Calibur $^{\mathrm{TM}}$, Becton-Dickinson).

Cell growth in a monolayer and in soft agar. To obtain a monolayer of cell growth, cells were plated at a density of $3 \times 10^{4}$ cells/well in 6-well plates containing DMEM with $10 \%$ FBS. The cell numbers were counted in triplicate after $2,4,6,8$ and 10 days using a hemocytometer to assess cell proliferation. For the soft agar determination of cell growth, a cell suspension $\left(1 \times 10^{4}\right.$ cells/well) in $1 \mathrm{ml} 0.2 \%$ Noble Agar DMEM with $10 \%$ FBS was overlaid onto a $35 \mathrm{~mm}$ dish containing a $0.5 \%$ agar base. Colonies $>0.2 \mathrm{~mm}$ in diameter were counted 21 days after culture. Soft agar assays were performed in triplicate.

Patients. The patient population consisted of 91 patients presenting with the International Federation of Gynecology and Obstetrics (FIGO) stage IB-IIB cervical cancers. Each of these patients underwent radical hysterectomy and pelvic lymphadnectomy at the Department of Obstetrics and Gynecology of Okayama University Hospital. Patients with neoadjuvant chemotherapy were excluded from this study. 
A
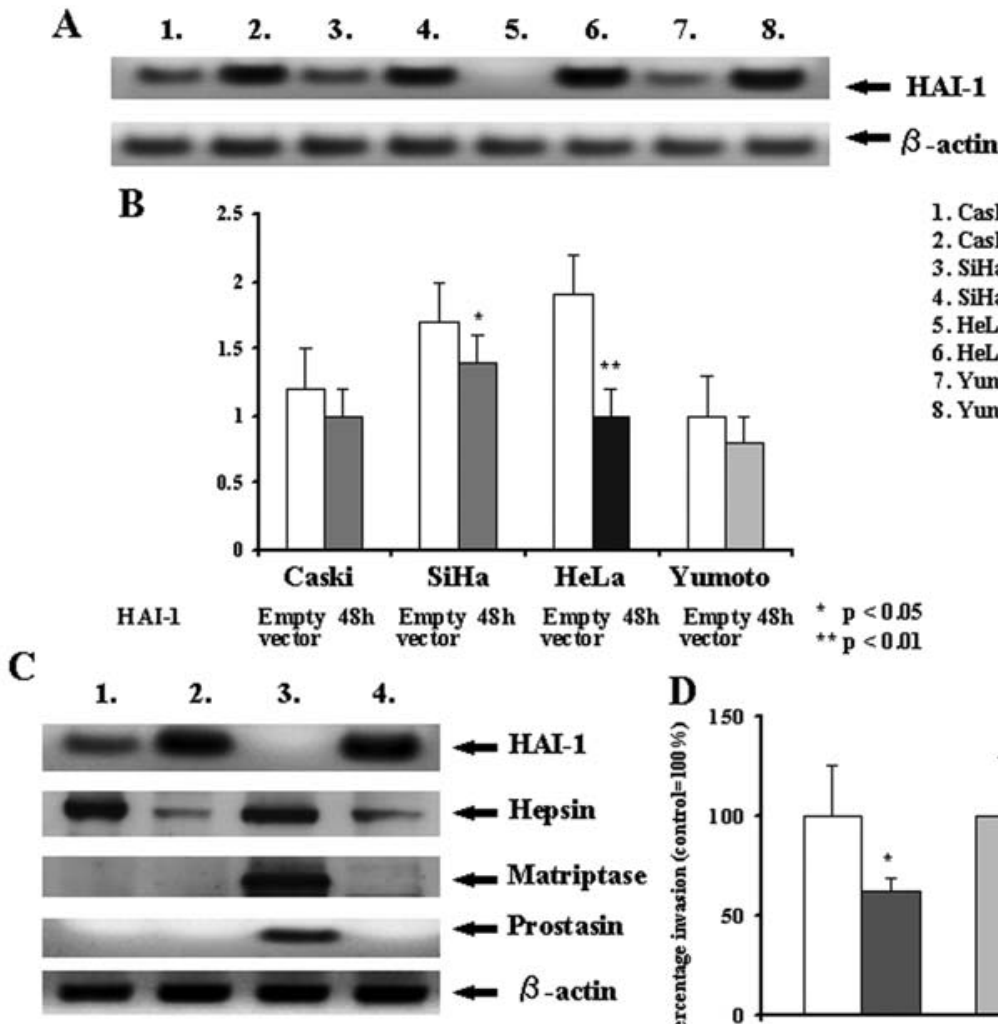

1. SiHa Empty vector

2. SiHa HAI-1

3. HeLa Empty vector

4. HeLa HAI-1

Figure 1. Evaluation of the transient transfection of the hepatocyte growth factor activator inhibitor-1 (HAI-1) vector into cervical cancer cells for 48 h. (A) Western blot analysis of HAI-1 expression after the transient transfection of the HAI-1 vector into Caski, SiHa, HeLa and Yumoto cervical cancer cells for 48 h. ß-actin antibody was used as the loading control in the same blot. (B) MTS assays of cell proliferation of Caski, SiHa, HeLa and Yumoto cervical cancer cells after transient transfection of the HAI-1 vector into cervical cancer cells for $48 \mathrm{~h}$. The assays were carried out for quadruplicate transfection experiments. (C) Western blot analysis of HAI-1, hepsin, matriptase and prostasin expression levels after transient transfection of the HAI-1 vector into SiHa and HeLa cervical cancer cells for $48 \mathrm{~h}$. B-actin antibody was used as the loading control in the same blot. (D) Matrigel invasion assay after transient transfectoin of the HAI-1 vector into SiHa and HeLa cervical cancer cells. Following incubation, membranes were removed from the insert and mounted on slides. The numbers of invading cells were counted under the microscope. The matrigel assays were performed in triplicate.

Tumor specimens were obtained at the time of surgery, immediately fixed in $10 \%$ neutral-buffered formation and then embedded in paraffin. The histological cell types were conducted according to the WHO classification as follows: 54 were classified as squamous cell carcinomas, 27 as adenocarcinomas and 10 as adenosquamous carcinomas. Clinical staging was assessed based on the FIGO staging system as follows: 45 were allocated to stage IB, 5 to stage IIA and 41 to stage IIB. The median age at the time of surgery was 45 years (range 27-66 years). Patients with lymph node metastasis, parametrial involvement, deep stromal invasion or marked lymph-vascular space involvement were treated with an adjuvant external whole pelvic irradiation, combination chemotherapy or chemoradiation. The disease-free survival (DFS) and overall survival (OS) rates were defined as the interval from the initial surgery to clinically or radiologically proven recurrence and death, respectively. The end date of the follow-up study for conducting the analysis was 30th September 2007, and median duration of the follow-up was 79 months (range 4-146).

Immunohistochemical analysis and staining evalution. Formalin-fixed paraffin-embedded sections at $4 \mu \mathrm{m}$ thick were deparaffinized with xylene and rehydrated in ethanol. Endogenous peroxidase activity was quenched by treatment with methanol containing $0.3 \%$ hydrogen peroxidase for $15 \mathrm{~min}$. Then, the sections were incubated with a primary antibody for HAI-1 at room temperature, followed by staining with a streptavidin-biotin-peroxidase kit (Nichirei, Tokyo, Japan). The sections were counterstained with hematoxylin. The levels of HAI-1 staining in the tumors were classified into three groups by scoring the percentages of positively stained cell: 2 , strong staining, $>50 \%$ of cells; 1 , moderate staining, $10-50 \%$ of cells; and weak staining, $<10 \%$ of cells. Two independent examiners with no prior knowledge of the patient clinical data conducted the microscopic evaluations. Controversial cases were evaluated using a conference microscope.

Statistical analysis. Statistical analyses were performed using the Mann-Whitney U test for comparison with the control and one-factor ANOVA followed by Fisher's protected least significance difference test for all-pair wise comparisons. Analyses were performed with the software package Stat View version 5.0 (Abacus Concepts, Berkeley, CA). Differences were considered significant at $\mathrm{p}<0.05$. 
A
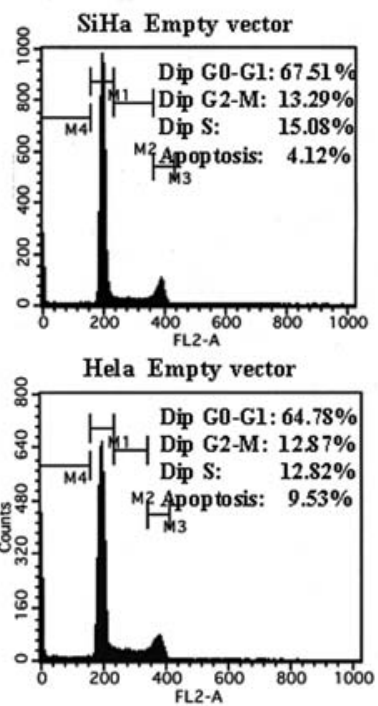

B

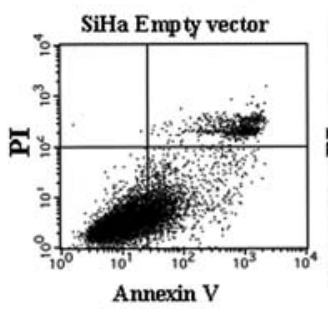

\begin{tabular}{c|c}
$0.02 \%$ & 8.52 \\
\hline $72.04 \%$ & $19.42 \%$
\end{tabular}

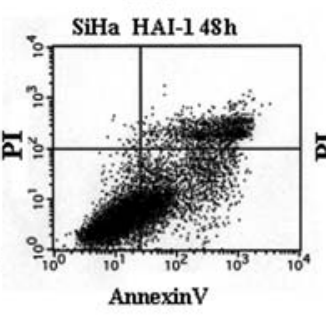

\begin{tabular}{r|r}
$\mathbf{0 . 2 3} \%$ & $13.71 \%$ \\
\hline $\mathbf{5 2 . 2 0} \%$ & $33.86 \%$
\end{tabular}

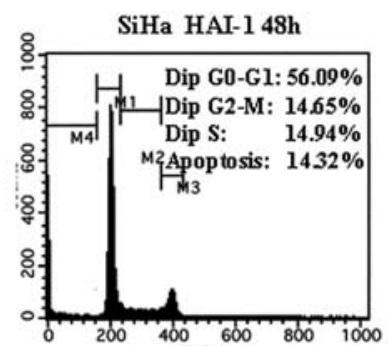

Hela HÄA-1 $48 \mathrm{~h}$

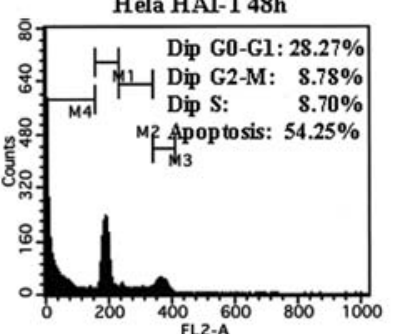

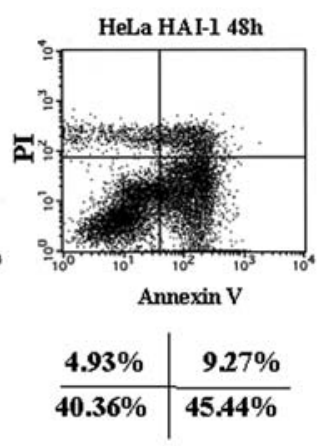

Figure 2. (A) Effects on the cell cycle by the transient transfectoin of the hepatocyte growth factor activator inhibitor-1 (HAI-1) vector into SiHa and HeLa cervical cancer cells for $48 \mathrm{~h}$. Representative cell cycle profiles, measured by propidium iodide (PI) staining with the percentages of cells in $\mathrm{G}_{0}-\mathrm{G}_{1}$ phase, $\mathrm{S}$ phase, $\mathrm{G}_{2}-\mathrm{M}$ phase and apoptosis phase are shown. (B) Effects on apoptosis by the transient transfection of the HAI-1 vector into SiHa and HeLa cervical cancer cells. Representative flow cytometric data of apoptosis in transient transfectoin of the HAI-1 vector into SiHa and HeLa cervical cancer cells for $48 \mathrm{~h}$.

\section{Results}

Expression of HAI-1 in cervical cancer cell line. We first examined HAI-1 expression in various cervical cancer cell lines. As shown in Fig. 1A, HAI-1 protein level was almost absent in the HeLa cell lines and abundantly expressed in Caski, SiHa and Yumoto cell lines. To examine functional role of HAI-1, transient transfection of the HAI-1 vector into cervical cancer cell lines which overexpress HAI-1 were generated as described in Materials and methods. The transient transfection of the HAI-1 vector caused significant increase HAI-1 protein levels in all fourth cervical cancer cell lines.

MTS assay by HAI-1. We used MTS assays to examine cell proliferation into Caski, SiHa, Hela and Yumoto cervical cancer cell lines caused by HAI-1. The transient transfection of the HAI-1 vector into these fourth cervical cancer cell line caused reduced cell growth by MTS assay. And, the inhibitory effect was most prominent in HeLa cervical cancer cell lines (Fig. 1B).

Effect of the target enzyme by HAI-1. Serine protease has been implicated in degradation of the extracellular matrix, and in modulation of cell-substratum adhesions in tumor cells associated with metastasis. The functional roles of HAI-1 were examined by transient transfection of the HAI-1 vector into $\mathrm{SiHa}$ and HeLa cell lines followed by Western blotting. The transient transfection of the HAI-1 vector into SiHa and HeLa cell lines caused a significant increase in expression of HAI-1. The levels of hepsin expression were decreased following transient transfection of the HAI-1 vector into $\mathrm{SiHa}$ and HeLa cells. The level of matriptase and prostasin expressions was significantly decreased by transient transfection of the HAI-1 vector into HeLa cells. Matriptase and prostasin expression was not detected in $\mathrm{SiHa}$ cells without or without transient transfection of the HAI-1 vector (Fig. 1C).

Matrigel invasion assay by HAI-1. We assessed the motility and invasiveness of $\mathrm{SiHa}$ and HeLa cells overexpressing HAI-1 by using a BioCoat Matrigel invasion chamber. Cells were plated on the upper surface of the membrane, and transient transfection of HAI-1 after $48 \mathrm{~h}$. Next, the cells invading to the bottom side of the membrane were stained and counted. The percentage of cells reaching the bottom of the filter were decreased to 58.32 and $38.81 \%$ at $48 \mathrm{~h}$ after transient transfection of the HAI-1 vector into $\mathrm{SiHa}$ and HeLa cells, respectively (Fig. 1D).

Cell cycle assay by HAI-1. Cells usually respond to genotoxic stress by activating cell cycle checkpoints and by blocking further progression into the cell cycle, allowing the cells to 


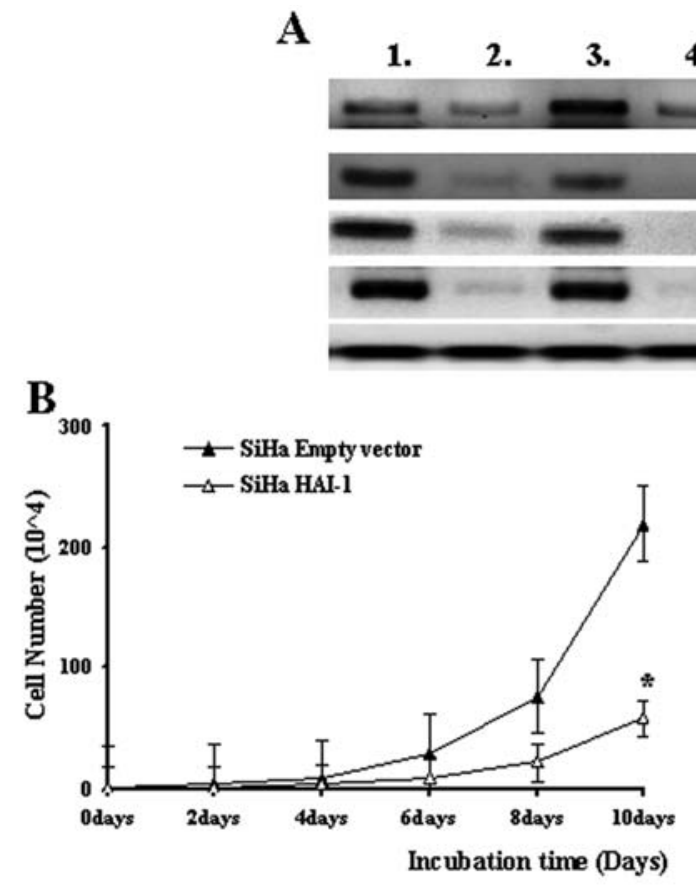

4.
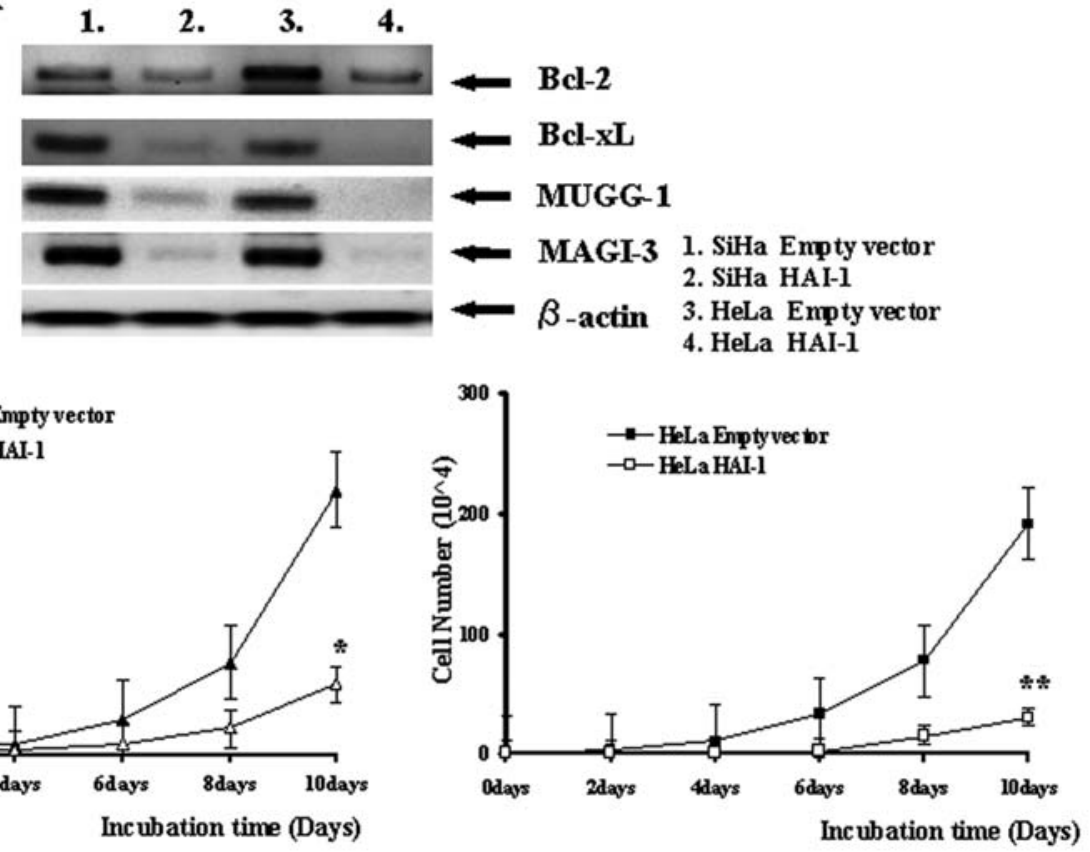

$\begin{aligned}{ }^{*} \mathrm{p} & <0.05 \\ { }^{* *} \mathrm{p} & <0.01\end{aligned}$

C Colony formation on soft agar of HAI-1 transfectants

and empty vector-transfected SiHa and HeLa cervical cancer cells

\begin{tabular}{|c|c|c|c|}
\hline Cell line & & Colonies/dish & Inhibitory effect (\%) \\
\hline $\mathrm{SiHa}$ & $\begin{array}{c}\text { Empty vector } \\
\text { HAI-1 }\end{array}$ & $\begin{array}{c}197.3 \pm 43.8 \\
28.2 \pm 3.9\end{array}$ & $\begin{array}{c}0 \\
85.7\end{array}$ \\
\hline HeLa & $\begin{array}{c}\text { Enpty vector } \\
\text { HAI-1 }\end{array}$ & $\begin{array}{r}15.5 \pm 4.8 \\
0.4 \pm 0.2\end{array}$ & $\begin{array}{c}0 \\
97 A^{* *}\end{array}$ \\
\hline
\end{tabular}

Figure 3. (A) Effects on the apoptotic and PDZ domain-containing protein pathway by the transient transfection of the hepatocyte growth factor activator inhibitor-1 (HAI-1) vector into SiHa and HeLa cervical cancer cells. The expression levels of Bcl-2, Bcl-xL, MUPP-1 and MAGI-3 were detected by Western blotting. B-actin antibody was used as the loading control in the same blot. Effects on cell growth by the transient transfectoin of the HAI-1 vector into SiHa and HeLa cervical cancer cells for $48 \mathrm{~h}$. (B) Monolayer growth of the transient transfectoin of the HAI-1 vector into SiHa and HeLa cervical cancer cells incubated for 2, 4, 6, 8 and 10 days in DMEM supplemented with 10\% FBS. Numbers represent data from triplicate experiments. (C) Colony formation on soft agar of the transient transfectoin of the HAI-1 vector into SiHa and HeLa cervical cancer cells. Numbers represent data from triplicate experiments.

repair DNA damage. The following cell cycle profiles were obtained from transient transfection of the HAI-1 vector into $\mathrm{SiHa}$ and HeLa cells. The cell cycle arrest was mainly observed at the apoptosis phases in the transient transfection of the HAI-1 vector into SiHa and HeLa cells, supporting the idea that HAI-1 acts as an inhibitor of cell growth (Fig. 2A).

Apoptotic assay by HAI-1. We used FITC-conjugated Annexin $\mathrm{V}$ assays to examine apoptosis expression after transient transfection of the HAI-1 vector into $\mathrm{SiHa}$ and HeLa cells. Representative flow cytometric data revealed that transient transfection of the HAI-1 vector for $48 \mathrm{~h}$ showed an increase in Annexin V-FITC- and propidium iodide (PI)positive signals. HAI-1 induced apoptosis in these cancer cells, which was assessed by Annexin V-FITC assay as shown in Fig. 2B. HAI-1 increased the total apoptotic and necrotic cells to 47.80 and $59.64 \%$ as compared with the control of 27.96 and $9.80 \%$ for $\mathrm{SiHa}$ and HeLa cells, respectively.
Furthermore, PI-negative and Annexin V-FITC-positive signals were significantly correlated more than PI-positive and Annexin V-FITC-negative signals, and PI-positive and Annexin V-FITC-positive signals. Therefore, HAI-1 was likely to regulate the early apoptosis process rather than late apoptosis and necrosis.

We also investigated the effect of HAI-1 on the protein levels of some apoptotic molecules such as anti-apoptotic Bcl-2 and Bcl-xL, and PDZ domain-containing MUPP-1 and MAGI-3 protein. As shown in Fig. 3A, the expression of Bcl-2, Bcl-xL, MUPP-1 and MAGI-3 were down-regulated in the transient transfection of the HAI-1 vector into $\mathrm{SiHa}$ and HeLa cells.

Cell growth in monolayers and anchorage-independent cell growth in soft agar by HAI-1. Effects of HAI-1 expression on cell proliferation were analyzed using the transient transfection of the HAI-1 vector into SiHa and HeLa cervical cancer cell 

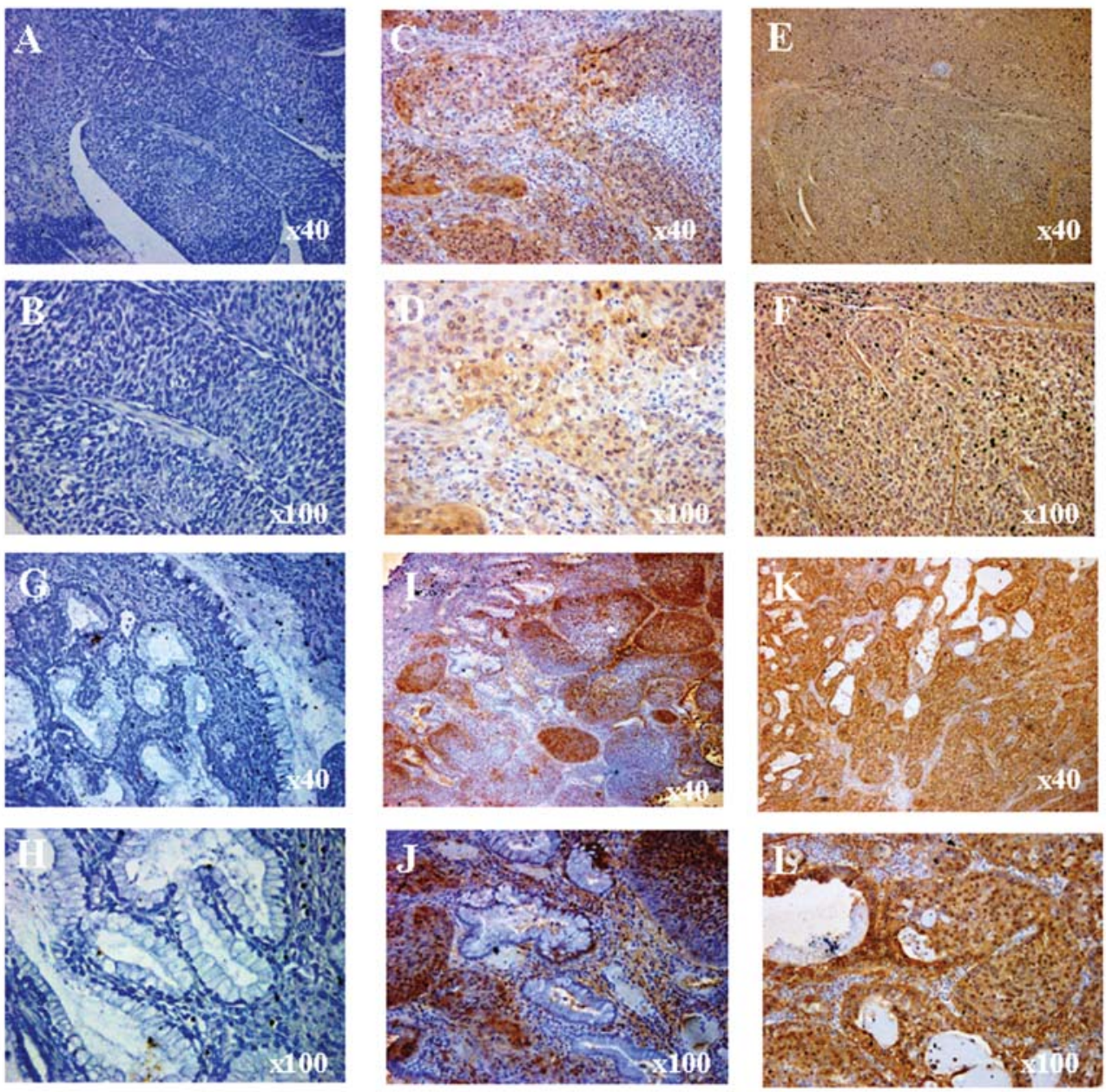

Figure 4. Representative immunostaining patterns of hepatocyte growth factor activator inhibitor-1 (HAI-1). (A) and (B) weak HAI-1 staining in squamous cell carcinoma. (C) and (D) moderate HAI-1 staining in squamous cell carcinoma. (E) and (F) strong HAI-1 staining in squamous cell carcinoma. (G) and (H) weak HAI-1 staining in adenocarcinoma. (I) and (J) moderate HAI-1 staining in adenosquamous cell carcinoma. (K) and (L) strong HAI-1 staining in adenosquamous cell carcinoma (original magnification $\mathrm{x} 40$ and $\mathrm{x} 100$ ). The relative strengths of the HAI-1 immunohistochemical staining was assessed qualitatively.

A

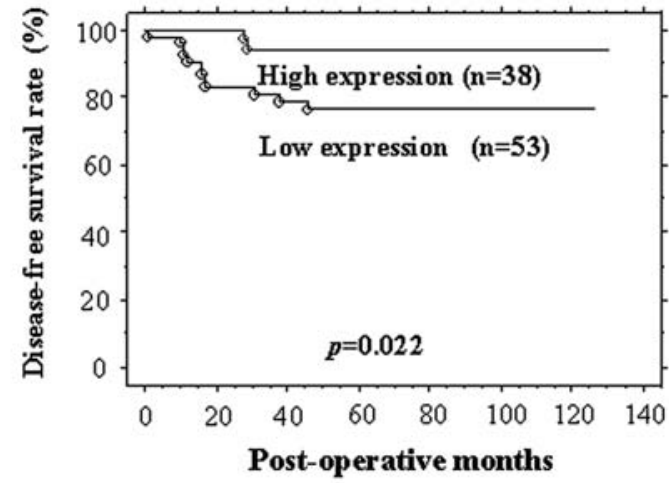

B

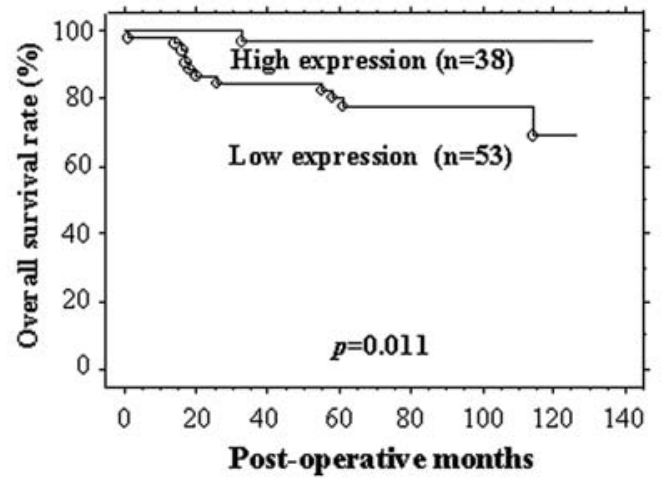

Figure 5. Kaplan-Meier plots for the disease-free and (A) overall survival (B) of the 91 patients with cervical cancer according to their hepatocyte growth factor activator inhibitor-1 (HAI-1) expression status. Low HAI-1 expression, score 0-1; high HAI-1 expression, score 2.

lines. We found a significant inhibitory effect of HAI-1 on cell growth transient transfection of the HAI-1 vector into both the SiHa and HeLa cell compared to control cells $(\mathrm{p}<0.05)$ (Fig. 3B). Furthermore, the colony forming assay showed that the transient transfection of the HAI-1 vector into $\mathrm{SiHa}$ and HeLa cell resulted in a significantly reduced number of colonies compared with control cells $(\mathrm{p}<0.01)$ (Fig. 3C). 
Table I. Association between HAI-1 and clinicopathological factors in cervical cancer.

\begin{tabular}{|c|c|c|c|c|c|c|}
\hline \multirow[b]{2}{*}{ Variable } & \multirow[b]{2}{*}{ Cases } & \multicolumn{3}{|c|}{ Staining } & \multirow[b]{2}{*}{$($ Mean $\pm \mathrm{SE})$} & \multirow[b]{2}{*}{$\mathrm{p}$-value } \\
\hline & & 0 & 1 & 2 & & \\
\hline Age (years) & & & & & & 0.716 \\
\hline$<50$ & 61 & 11 & 23 & 27 & $1.26 \pm 0.75$ & \\
\hline$\geq 50$ & 30 & 5 & 14 & 11 & $1.20 \pm 0.71$ & \\
\hline FIGO stage & & & & & & $0.013^{\mathrm{a}}$ \\
\hline I & 45 & 5 & 16 & 24 & $1.42 \pm 0.69$ & \\
\hline II & 46 & 11 & 21 & 14 & $1.04 \pm 0.73$ & \\
\hline Histological type & & & & & & 0.280 \\
\hline Non-SCC & 37 & 8 & 16 & 13 & $1.14 \pm 0.75$ & \\
\hline $\mathrm{SCC}$ & 54 & 8 & 21 & 25 & $1.31 \pm 0.72$ & \\
\hline Tumor size $(\mathrm{cm})$ & & & & & & $0.002^{\mathrm{a}}$ \\
\hline$\leq 4$ & 74 & 10 & 28 & 36 & $1.35 \pm 0.71$ & \\
\hline$>4$ & 17 & 6 & 9 & 2 & $0.76 \pm 0.66$ & \\
\hline Stromal invasion & & & & & & $<0.001^{\mathrm{a}}$ \\
\hline$\leq 2 / 3$ & 45 & 4 & 11 & 30 & $1.58 \pm 0.66$ & \\
\hline$>2 / 3$ & 46 & 12 & 26 & 8 & $0.91 \pm 0.66$ & \\
\hline Vaginal invasion & & & & & & $0.031^{\mathrm{a}}$ \\
\hline Negative & 77 & 12 & 29 & 36 & $1.31 \pm 0.73$ & \\
\hline Positive & 14 & 4 & 8 & 2 & $0.85 \pm 0.66$ & \\
\hline Parametrial invasion & & & & & & $0.012^{\mathrm{a}}$ \\
\hline Negative & 68 & 10 & 24 & 34 & $1.35 \pm 0.73$ & \\
\hline Positive & 23 & 6 & 13 & 4 & $0.91 \pm 0.66$ & \\
\hline Lymph node metastasis & & & & & & $0.019^{\mathrm{a}}$ \\
\hline Negative & 72 & 10 & 28 & 34 & $1.33 \pm 0.71$ & \\
\hline Positive & 19 & 6 & 9 & 4 & $0.89 \pm 0.73$ & \\
\hline LVS involvement & & & & & & $0.002^{\mathrm{a}}$ \\
\hline Negative & 44 & 4 & 15 & 25 & $1.48 \pm 0.66$ & \\
\hline Positive & 47 & 12 & 22 & 13 & $1.02 \pm 0.74$ & \\
\hline Ovarian metastasis & & & & & & 0.170 \\
\hline Negative & 88 & 15 & 35 & 38 & $1.26 \pm 0.73$ & \\
\hline Positive & 3 & 1 & 2 & 0 & $0.67 \pm 0.58$ & \\
\hline
\end{tabular}

${ }^{a}$ Mann-Whitney U test; FIGO, International Federation of Gynecology; LVS, lymph-vascular space.

Immunoassays by HAI-1. HAI-1 expression in human cervical cancer specimens was examined by immunoassays. The representative immunoassaying patterns of HAI-1 are shown in Fig. 4. Weak HAI-1 staining was observed in 16 cases (17.6\%), moderate HAI-1 staining in 37 cases $(40.6 \%)$ and strong HAI-1 staining in 38 cases $(41.8 \%)$.

Table I shows the distribution of cases scored as positive for each of the biological parameters examined, according to the clinicopathological characteristics in the overall population. As expected, the results showed a statistically significant association with clinicopathological parameters such as stage $(p=0.013)$, tumor size $(p=0.002)$, stromal invasion $(\mathrm{p}<0.001)$, vaginal invasion $(\mathrm{p}=0.031)$, parametrial invasion $(\mathrm{p}=0.012)$, lymph-node metastasis $(\mathrm{p}=0.019)$ and LVS involvement $(\mathrm{p}=0.002)$, but age, histological type and ovarian metastasis were not statistically significant (MannWhitney U test, $\mathrm{p}<0.05$ ).

Univariate survival analysis. The results of the univariate survival analyses of other variables are shown in Table II. Overall, HAI-1 was most significantly exhibited on DFS and OS analysis of the prognostic factor for cervical cancer using the log-rank test. The DFS and OS curves of 91 cervical cancer patients according to their HAI-1 expression status are 
Table II. DFS and OS analysis of prognostic factor using the log-rank test in cervical cancer.

\begin{tabular}{|c|c|c|c|c|c|}
\hline Variable & Cases & $\begin{array}{c}\text { Estimated } \\
\text { 5-year DFS (\%) }\end{array}$ & p-value ${ }^{a}$ & $\begin{array}{c}\text { Estimated } \\
\text { 5-year OS (\%) }\end{array}$ & $\mathrm{p}$-value ${ }^{\mathrm{a}}$ \\
\hline Age (years) & & & 0.392 & & 0.649 \\
\hline$<50$ & 61 & 86.9 & & 86.9 & \\
\hline$\geq 50$ & 30 & 80.0 & & 83.3 & \\
\hline FIGO stage & & & 0.263 & & 0.392 \\
\hline I & 45 & 88.9 & & 88.9 & \\
\hline II & 46 & 80.4 & & 82.6 & \\
\hline Histological type & & & 0.172 & & 0.090 \\
\hline Non-SCC & 37 & 78.4 & & 78.4 & \\
\hline SCC & 54 & 88.9 & & 90.7 & \\
\hline Tumor size $(\mathrm{cm})$ & & & 0.075 & & $0.048^{\mathrm{a}}$ \\
\hline$\leq 4$ & 74 & 87.8 & & 89.2 & \\
\hline$>4$ & 17 & 70.6 & & 70.6 & \\
\hline Stromal invasion & & & $0.004^{\mathrm{a}}$ & & $0.008^{\mathrm{a}}$ \\
\hline$\leq 2 / 3$ & 45 & 95.6 & & 95.6 & \\
\hline$>2 / 3$ & 46 & 73.9 & & 76.1 & \\
\hline Vaginal invasion & & & 0.901 & & 1 \\
\hline Negative & 77 & 84.4 & & 85.7 & \\
\hline Positive & 14 & 85.7 & & 85.7 & \\
\hline Parametrial invasion & & & $0.021^{\mathrm{a}}$ & & $0.010^{\mathrm{a}}$ \\
\hline Negative & 68 & 89.7 & & 91.2 & \\
\hline Positive & 23 & 69.6 & & 69.6 & \\
\hline Lymph node metastasis & & & $<0.001^{\mathrm{a}}$ & & $<0.001^{\mathrm{a}}$ \\
\hline Negative & 72 & 93.1 & & 93.1 & \\
\hline Positive & 19 & 52.6 & & 57.9 & \\
\hline LVS involvement & & & $<0.001^{\mathrm{a}}$ & & $0.002^{\mathrm{a}}$ \\
\hline Negative & 44 & 97.7 & & 97.7 & \\
\hline Positive & 47 & 72.3 & & 74.5 & \\
\hline Ovarian metastasis & & & 0.380 & & 0.423 \\
\hline Negative & 88 & 84.2 & & 85.2 & \\
\hline Positive & 3 & 66.7 & & 66.7 & \\
\hline HAI-1 & & & $0.023^{\mathrm{a}}$ & & $0.007^{\mathrm{a}}$ \\
\hline Low $(0-1)$ & 53 & 77.4 & & 77.4 & \\
\hline $\operatorname{High}(2)$ & 38 & 94.7 & & 97.4 & \\
\hline
\end{tabular}

${ }^{a}$ Mann-Whitney U-test; FIGO, International Federation of Gynecology and Obstetrics; LVS, lymph-vascular space.

shown in Fig. 5A and B, respectively. The DFS and OS rates of patients exhibiting high HAI-1 expression (score 2) were significantly higher than those of patients exhibiting low HAI- 1 expression (score $0-1)(p=0.022$ and $p=0.011$, respectively) (Mann-Whitney U test, $\mathrm{p}<0.05$ ).

\section{Discussion}

Cervical cancer is the most important manifestation of genital HPV infection. HPV viruses encode the E6 and E7 oncogenes, which are essential for malignant transformation as well as maintenance of the malignant phenotype of cervical cancer. The E6 protein forms a tertiary complex with ubiquitinmediated degradation, including p53 and PDZ domaincontaining protein (MUGG-1 and MAGI-3) (22-24). The E7 protein binds directly to inactivate a number of cell cycle regulatory proteins, including family of retinoblastoma protein (25). Several studies have demonstrated that these oncogenes make ideal targets for gene-specific therapy for cervical cancer. However, to date, their effectiveness has 
been limited. It is now widely accepted that new approaches for the treatment of cervical cancer are pivotal in further improving the prognosis of this disease.

This is the first study to investigate the role of HAI-1 and evaluate its clinical importance in cervical cancer. HAI- 1 is a Kunitz-type serine protease inhibitor that has a broad inhibitory spectrum against serine proteases. HAI-1 is an endogenous inhibitor of hepsin, matriptase and prostasin. Hepsin, matriptase and prostatsin are a serine proteinase domain, and show enhanced expression in a variety of tumor tissues (26). Hepsin and matriptase has been proposed to initiate signaling and proteolytic cascades through its ability to activate pro-uPA, and matriptase is known to interact with prostasin (7-10). In this study, hepsin, matriptase and prostasin were significantly inhibited by HAI-1 in cervical cancer cell lines (Fig. 1C).

Parr and colleagues have reported that HAI-1 expression significantly enhanced the migratory, proliferative and invasive nature of breast cancer cell lines (27). However, the impact on apoptosis from HAI-1 overexpression remains unclear. In this report, we observed significant inhibition which resulted in apoptosis by HAI-1, as shown in Fig. 2A and B. Furthermore, HAI-1 was likely to regulate the early apoptosis process. To trace the steps in the apoptotic cascade, we evaluated the activation of pro- and anti-apoptotic protein (28-30). HAI-1 was able to down-regulate both Bcl-2 and Bcl-xL, thereby inducing apoptosis (Fig. 3A).

The E6 and E7 proteins of HPV immortalize, at least in part, the inactivation of the tumor suppressor proteins p53 and PDZ domain-containing protein and RB protein (22-25). These tumor suppressor proteins also regulate the expression of pro- and anti-angiogenic factors by cells. For this reason, experiments were conducted to determine the role of HAI-1 on p53, PDZ domain-containing protein (hDlg, MUGG-1 and MAGI-3) and RB proteins. The expression of PDZ domaincontaining protein (MUGG-1 and MAGI-3) was downregulated in the cells transiently transfected with HAI-1 (Fig. 3A). However, HAI-1 was not correlated with the levels of the p53, hDlg and RB protein (data not shown). Overall, HAI- 1 shows potential inhibitory effects mediated by reduction of hepsin, matriptase and prostasin, which leads to apoptosis through a reduction in the level of Bcl-2, Bcl-xL, MUPP-1 and MAGI-3.

In clinical case, prostate, breast and gastric cancer has been reported that the reduced expression of HAI-1 is possibly involved in the progression of these cancers (18-20). The current study, the immunohistochemistry of cervical cancers from chemo-naive patients showed decreased HAI-1 protein expression that increased with stage of cancer, tumor size, stromal invasion, vaginal invasion, parametrial invasion, lymph-node metastasis and LVS involvement. Interestingly, a low HAI-1 immunostaining pattern was significantly associated with poor prognosis in cervical cancer (Fig. 5A and B). These findings all indicate that HAI-1 protein could be an important tool for identifying patients with a favorable prognostic marker of cervical cancer.

In summary, these studies have revealed a critical role for HAI-1 in the disruption of the basement membrane of cervical cancer. These findings identify HAI-1 as a favorable prognostic marker for patients and could be considered as a therapeutic target for certain approaches to the treatment of cervical cancer.

\section{Acknowledgments}

This work was supported in part by Okayama Health \& Ecology foundation 2008 (K. Nakamura). We are grateful to Dr H. Kataoka for providing the full-length HAI-1 cDNA construct encoding the HAI-1 protein to the Department of Oncopathology and Regenerative Biology (Department of Pathology, Faculty of Medicine, University of Miyazaki, Japan).

\section{References}

1. Wang SS and Hildesheim A: Chapter 5: Viral and host factors in human papillomavirus persistence and progression. J Natl Cancer Inst Monogr 31: 35-40, 2003.

2. Lee JW, Yong Song S, Choi JJ, Lee SJ, Kim BG, Park CS, Lee JH, Lin CY, Dickson RB and Bae DS: Increased expression of matriptase is associated with histopathologic grades of cervical neoplasia. Hum Pathol 36: 626-633, 2005.

3. Galkin AV, Mullen L, Fox WD, Brown J, Duncan D, Moreno O, Madison EL and Agus DB: CVS-3983, a selective matriptase inhibitor, suppresses the growth of androgen independent prostate tumor xenografts. Prostate 61: 228-235, 2004.

4. Riddick AC, Shukla CJ, Pennington CJ, Bass R, Nuttall RK, Hogan A, Sethia KK, Ellis V, Collins AT, Maitland NJ, Ball RY and Edwards DR: Identification of degradome components associated with prostate cancer progression by expression analysis of human prostatic tissues. Br J Cancer 92: 2171-2180, 2005.

5. Kang JY, Dolled-Filhart M, Ocal IT, Singh B, Lin CY, Dickson RB, Rimm DL and Camp RL: Tissue microarray analysis of hepatocyte growth factor/Met pathway components reveals a role for Met, matriptase, and hepatocyte growth factor activator inhibitor 1 in the progression of node-negative breast cancer. Cancer Res 63: 1101-1105, 2003.

6. Oberst MD, Johnson MD, Dickson RB, Lin CY, Singh B, Stewart M, Williams A, al-Nafussi A, Smyth JF, Gabra H and Sellar GC: Expression of the serine protease matriptase and its inhibitor HAI-1 in epithelial ovarian cancer: correlation with clinical outcome and tumor clinicopathological parameters. Clin Cancer Res 8: 1101-1107, 2002.

7. Lee SL, Dickson RB and Lin CY: Activation of hepatocyte growth factor and urokinase/plasminogen activator by matriptase, an epithelial membrane serine protease. J Biol Chem 275: 36720-36725, 2000.

8. Moran P, Li W, Fan B, Vij R, Eigenbrot C and Kirchhofer D: Pro-urokinase-type plasminogen activator is a substrate for hepsin. J Biol Chem 281: 30439-30446, 2006.

9. Takeuchi T, Harris JL, Huang W, Yan KW, Coughlin SR and Craik CS: Cellular localization of membrane-type serine protease 1 and identification of protease-activated receptor-2 and single-chain urokinase-type plasminogen activator as substrates. J Biol Chem 275: 26333-26342, 2000.

10. Netzel-Arnett S, Currie BM, Szabo R, Lin CY, Chen LM, Chai KX, Antalis TM, Bugge TH and List K: Evidence for a matriptaseprostasin proteolytic cascade regulating terminal epidermal differentiation. J Biol Chem 281: 32941-32945, 2006.

11. Kirchhofer D, Peek M, Lipari MT, Billeci K, Fan B and Moran P: Hepsin activates pro-hepatocyte growth factor and is inhibited by hepatocyte growth factor activator inhibitor-1B (HAI-1B) and HAI-2. FEBS Lett 579: 1945-1950, 2005.

12. Kataoka H, Miyata S, Uchinokura S and Itoh H: Roles of hepatocyte growth factor (HGF) activator and HGF activator inhibitor in the pericellular activation of $\mathrm{HGF} / \mathrm{scatter}$ factor. Cancer Metastasis Rev 22: 223-236, 2003.

13. Fan B, Wu TD, Li W and Kirchhofer D: Identification of hepatocyte growth factor activator inhibitor-1B as a potential physiological inhibitor of prostasin. J Biol Chem 280: 34513-34520, 2005.

14. Kataoka H, Shimomura T, Kawaguchi T, Hamasuna R, Itoh H, Kitamura N, Miyazawa K and Koono M: Hepatocyte growth factor activator inhibitor type 1 is a specific cell surface binding protein of hepatocyte growth factor activator (HGFA) and regulates HGFA activity in the pericellular microenvironment. J Biol Chem 275: 40453-40462, 2000. 
15. Lin CY, Anders J, Johnson M and Dickson RB: Purification and characterization of a complex containing matriptase and a Kunitz-type serine protease inhibitor from human milk. J Biol Chem 274: 18237-18242, 1999.

16. Herter S, Piper DE, Aaron W, Gabriele T, Cutler G, Cao P, Bhatt AS, Choe Y, Craik CS, Walker N, Meininger D, Hoey T and Austin RJ: Hepatocyte growth factor is a preferred in vitro substrate for human hepsin, a membrane-anchored serine protease implicated in prostate and ovarian cancers. Biochem J 390: 125-136, 2005.

17. List K, Szabo R, Molinolo A, Sriuranpong V, Redeye V, Murdock T, Burke B, Nielsen BS, Gutkind JS and Bugge TH: Deregulated matriptase causes ras-independent multistage carcinogenesis and promotes ras-mediated malignant transformation. Genes Dev 19: 1934-1950, 2005.

18. Saleem M, Adhami VM, Zhong W, Longley BJ, Lin CY, Dickson RB, Reagan-Shaw S, Jarrard DF and Mukhtar H: A novel biomarker for staging human prostate adenocarcinoma: overexpression of matriptase with concomitant loss its inhibitor, hepatocyte growth factor activator inhibitor-1. Cancer Epidemiol Biomarkers Prev 15: 217-227, 2006.

19. Parr C, Watkins G, Mansel RE and Jiang WG: The hepatocyte growth factor regulatory factors in human breast cancer. Clin Cancer Res 10: 202-211, 2004.

20. Zeng L, Cao J and Zhang X: Expression of serine protease SNC19/matriptase and its inhibitor hepatocyte growth factor activator inhibitor type 1 in normal and malignant tissues of gastrointestinal tract. World J Gastroenterol 11: 6202-6207, 2005.

21. Mitsuhashi A, Tanaka H, Tanaka N, Sugita M, Shirasawa H, Tokita H, Eda H and Sekiya S: Establishment and characterization of a new HPV-negative squamous cell carcinoma cell line (Yumoto) from the human uterine cervix. Gynecol Oncol 70: 339-347, 1998

22. Huibregtse JM, Scheffner M and Howley PM: Localization of the E6-AP regions that direct human papillomavirus E6 binding, association with $\mathrm{p} 53$, and ubiquitination of associated proteins. Mol Cell Biol 13: 4918-4927, 1993.
23. Thomas M, Glaunsinger B, Pim D, Javier R and Banks L: HPV E6 and MAGUK protein interactions: determination of the molecular basis for specific protein recognition and degradation. Oncogene 20: 5431-5439, 2001.

24. Thomas M, Laura R, Hepner K, Guccione E, Sawyers C, Lasky L and Banks L: Oncogenic human papillomavirus E6 proteins target the MAGI-2 and MAGI-3 proteins for degradation. Oncogene 21: 5088-5096, 2002.

25. Münger K, Werness BA, Dyson N, Phelps WC, Harlow E and Howley PM: Complex formation of human papillomavirus E7 proteins with the retinoblastoma tumor suppressor gene product. EMBO J 8: 4099-4105, 1989.

26. Netzel-Arnett S, Hooper JD, Szabo R, Madison EL, Quigley JP, Bugge TH and Antalis TM: Membrane anchored serine proteases: a rapidly expanding group of cell surface proteolytic enzymes with potential roles in cancer. Cancer Metastasis Rev 22: 237-258, 2003.

27. Parr $\mathrm{C}$ and Jiang WG: Hepatocyte growth factor activation inhibitors (HAI-1 and HAI-2) regulate HGF-induced invasion of human breast cancer cells. Int J Cancer 119: 1176-1183, 2006.

28. Dole MG, Jasty R, Cooper MJ, Thompson CB, Nuñez G and Castle VP: Bcl-xL is expressed in neuroblastoma cells and modulates chemotherapy-induced apoptosis. Cancer Res 55: 2576-2582, 1995.

29. Farrow SN, White JH, Martinou I, Raven T, Pun KT, Grinham CJ, Martinou JC and Brown R: Cloning of a bcl-2 homologue by interaction with adenovirus E1B 19K. Nature 374: 731-733, 1995.

30. Cheng EH, Levine B, Boise LH, Thompson CB and Hardwick JM: Bax-independent inhibition of apoptosis by Bcl-XL. Nature 379: 554-556, 1996. 